\title{
Does Animation Facilitate Better Learning in Primary Education? A Comparative Study of Three Different Subjects
}

\author{
M. Shreesha',2, Sanjay Kumar Tyagi, \\ ${ }^{1}$ College of Applied Sciences, Ibri, Oman \\ ${ }^{2}$ Ministry of Higher Education, Muscat, Oman \\ Email: shreeshapunacha@gmail.com
}

Received 31 May 2016; accepted 15 August 2016; published 18 August 2016

Copyright (C) 2016 by authors and Scientific Research Publishing Inc.

This work is licensed under the Creative Commons Attribution International License (CC BY). http://creativecommons.org/licenses/by/4.0/

c) (i) Open Access

\section{Abstract}

The research and innovation in the field of computer and technology has made significant contribution for the development of new pedagogical strategies in all levels of education. The use of digital tools like animation has changed the way of providing education, especially in primary school level, adding an element of entertainment to the process of teaching and learning. It is assumed that the use of animated instructional material can help to present a complex concept in a simple form, create more interest about the subject, motivate the pupil for better learning, increase the accuracy of the message and play a crucial role in improving the students' academic performance. Against this background, the present paper attempts to assess the efficacy of animation on different subjects in primary education. Here, in the study, an experiment has been conducted using animation to teach three subjects Mathematics, Language and Science; and students' performance was compared and analyzed using fuzzy statistical tools.

\section{Keywords}

Teaching, Learning, Education, ICT, Animation

\section{Introduction}

The advent of computers has changed the method of communication in modern day classrooms. Computermediated communication in classroom is getting more and more popular nowadays. Computer-mediated communication often referred to as CMC, is human interaction using networked computer environments. It includes human communication and information shared through communication networks (Pearson et al., 2011). 
In a classroom, teachers select and arrange what the students are supposed to learn (the content), decide how best to help them learn (the instructional strategy), and determine how success in learning will be determined and how the students' progress will be communicated by and to them (evaluation/feedback) (Wrench et al., 2009). Teachers consciously and strategically make decisions about both what is communicated and how it is communicated in a classroom. Normally, in a traditional classroom setup, teachers use interpersonal communication techniques. But, the digital revolution has opened new ways for teaching and learning with the use of e-mail messages, discussion group threads, instant messages, text messages and multimedia in a classroom.

According to Chizmar and Walbert (1999), the new technology allows the teacher to move from the "sage on the stage" to the "guide at the side". When technologies are infused into the curriculum, the teacher's role shifts from, being primarily, an information source to a facilitator, a coach, a guide, and a co-learner. Marshall makes many strong claims on the effectiveness of use digital tools in education. He says, "Historical evidence suggests that technology can, and did teach, in more than 50 research studies addressing voice, video, and computerbased learning provide conclusive evidence that students can, and do, learn from educational technologies" (as cited in Molenda \& Sullivan, 2003: p. 15). Fine and Thornbury (2006) think that in the twenty-first century the computer probably inspires the most curiosity and respect from young children.

One of the most popular digital tools which inspires and motivate students for better learning in primary education is-Animation. According to Betrancourt and Tversky's "Animation refers to any application, which generates series of frames so that each frame appears an alternative for the previous one, and where the sequence of frames are determined either by the designer or the user” (as cited Betrancourt and Chassot, 2008: p. 141).

\section{Literature Review}

For successful communication in the field of education, a teacher should facilitate enjoyment in classroom learning (Easingwood, 2000). Animation has been effectively achieving this in modern day classroom. Studies conducted by various researchers prove it. Mayer (2008) after doing several studies came to the conclusion that cartoon animation is exceedingly successful in engaging its audience; even the most bizarre events are easily comprehended applying animation.

In traditional classroom setup, instructor often uses “chalk and talk” method for teaching. Usually, learner's attention in the traditional classroom is directed by the explanation of the instructor and the text or static diagram written on the blackboard. When students see a static diagram in the classroom, they may have to mentally animate it to understand how the system works. Whereas, if they view the same course content in animated form they merely have to perceive as it is. Mental animation depends on the prior knowledge of the mechanics as well as spatial ability (Hegarty \& Kriz, 2008).

A good animation can improve the quality of communication by focusing on specificity and accuracy of the message, paving way for swift integration of new information with prior knowledge of pupil. Thus, the students with a high level of prior knowledge are able to assess the "gaps" between the internal and external information they have. There are several reasons to believe animation could enhance the prior knowledge as well (Hegarty \& Kriz, 2008).

A study by Baylor and Ryu comparing the static images and animated versions of a learning agent, found that the animated versions were rated as being more "engaging and credible” (as cited in Rogers, 2008: p. 295). In his research, attempted to find out the reasons behind the efficacy of animation in supporting the learning process in two different circumstances, i.e., when animated agents are used as learning companions versus when they are used as virtual characters in an interactive narrative. In both the instances, it appeared that the use of animated agents results in a highly engaging user experience, enabling children to more readily understand what is being said, acted out and being asked for.

Animation can facilitate a deeper learning by providing multiple perspectives to complex concepts (Narayanan \& Hegarty, 1998). Schnotz and Rasch (2008) argues that animated pictures can also direct the observer's attention to important aspects of the display, convey procedural knowledge, demonstrate the dynamics of subject matter and allow explanatory learning through manipulating a displayed object. Even, Betrancourt \& Chassot (2008) in their study on instructional uses of animation, found that animation promotes better understanding due to its visualization.

However, the level of impact of animation may not be the same on everyone in a classroom. "Learning with animation poses serious challenges to the human information processing system. Animation need not to be su- 
perior to static images always in promoting learning. The effectiveness of animation often depends on how it influences on the learners cognitive processing” (Mayor, 2008). Many studies conducted by Mayer and Chandler (2001) show that the poor knowledge level students particularly get benefit from the addition of text to diagrams. Mayer (2008) compared the performance of two groups of students, low and high knowledge group, in learning a physics system either through the diagram alone or through the combination of diagram and text. His study concluded that the high knowledge learners were somewhat successful in understanding the systems from diagrams alone, low-knowledge learners scored higher on retention tests when they received both text and diagrams. An animation has the capacity to present the dynamic aspects of an issue directly and explicitly (as cited in Younger \& Narayanan, 2008: p. 237).

However, a few researchers argue that the use of animation in a classroom can be detrimental to the learning process. Lowe has come up with a phenomenon called 'underwhelming' where there will be a negative effect on learning from animated graphics due to the insufficient processing of pictorial information (as cited in Betrancourt \& Chassot, 2008: p. 148). Comprehension of an animated presentation may also be compromised if learners lack the conceptual and strategic skills required to extract the relevant information. He also found in his previous studies that, novice learners tend to apply ineffective strategies when interrogating the complex, interactive animation.

\section{Significance of the Study}

Researches done in the recent past are providing enough evidence to believe that the use of modern technological tools like animation is helping to facilitate students' academic performance, especially in primary educational level. However, the effectiveness of animation may vary from subject to subject depending on various factors. The current study focuses on this aspect. The study examines the efficacy of use of animation instructional material in facilitating students learning taking three different subjects-Mathematics, Science, and Language. It throws throws light to on the degree of improvement and differences in the students performance when students study different subjects using animation instructional material in elementary school. The findings also will enable to get several insights into the issues related to teaching and learning with animation. Furthermore, this will also help to set the right direction for designing and developing animated instructional material for primary education.

\section{Objective of the Study}

The study aims:

- To examine the effectiveness of animation in felicitating students learning in primary educational level.

- To compare and assess the students' academic performance when animation instructional material used to teach different subjects.

\section{Research Hypothesis}

The studies done by various researchers on animation show that it plays a positive role in improving learning among students. Animation helps to engage its audience (Mayer, 2008). The use of animation in classroom will successfully involve students and motivate them for better teaching and learning. The use of animation help to memorize the course content better. Besides, it can provide a base for the reduction of cognitive load of the students as it can present a complex topic in a simpler form (Schontz \& Rasch, 2008). Therefore, when animation instructional material is used for teaching various subjects it should positive impact on the students' performance in all the subjects. Considering this, following hypotheses are formed for the study:

$\boldsymbol{H}_{\mathbf{0}}$ : Animation will facilitate student's performance equally when it is used for teaching different subjects.

$\boldsymbol{H}_{1}$ : Animation will not facilitate student's performance equally when it is used for teaching different subjects.

\section{Research Methodology}

\subsection{Research Design}

The current study is undertaken using the experimental and observational method. In the experiment conducted, the students were divided into groups-experiment and control. In experimental group, animation instructional material used to teach the course. But in control group, traditional "chalk and talk" method was adopted. Per- 
formance of the students of in both the groups were compared.

Naturalistic observational technique was used to understand the behavioral patterns of students in the classroom. Students' level of involvement in the study, difficulties faced while learning and their reaction to the teaching technique adopted was recorded and analyzed.

\subsection{Sampling Procedure}

In the current study cluster sampling technique was used. Students from two schools from Karnataka, a state of India were randomly selected for the study considering the diversity in the geographical area, educational standard, socio-economic condition and technological exposure of the primary school students. In the selected school, the experiment was conducted in the second, fourth and sixth standard. In each class, students were divided into two groups-control and experimental group, using simple random sampling technique.

\subsection{Data Collection Tools}

For the experimental study, three different subjects were randomly selected-Mathematics Language (Kannada) and Science. The animated instructional material was collected on these subjects from the pool of animated instructional material prepared by Ajim Premji foundation which is approved by the Govt. of Karnataka and currently being used in primary schools of Karnataka. In the selected subjects a particular topic was identified for the study considering the syllabus of second, fourth and sixth standard students. While selecting the topic and finalizing the animation instructional material, two primary school teachers were consulted to make sure that the selected topics match the syllabus and standard of current primary school education. During the course of the experimental study, for every subject in every class, two question papers, one for pre-test and another one for post-test was prepared separately. While preparing the question paper, care has been taken to make sure that the selected topics are covered in animation content as well. In both, pre-test and post-test, the difficulty levels of questions were same.

A qualified primary school teacher has conducted classes in the selected schools. The teacher has conducted the class using charts, games and chalks and talk method, which is appropriate to the concerned subjects in the control group. And, the same subject and topics were covered with the help of animation in the experimental group. Throughout the study, a single teacher had handled the class in the schools to maintain uniformity in teaching method and instructional materials used, and to avoid the possible influence of extraneous factors in the study. In both, control and experimental group, 45 minutes were given for pre-test and post-test and 2 hours for teaching. The maximum marks in each exam students could gain were 20.

\subsection{Data Analysis Methods}

A contingency table for the marks of pre-test and post-test for urban and rural students was prepared. The mean and standard deviation was calculated in every set, for both pre-test and post-test using IBM SPSS. In order to examine the effectiveness of the teaching method, in control and experimental group, the difference between pre-test and post-test scores were calculated and compared. And the testing of the hypothesis was done by using fuzzy set theory based statistical tools.

\section{Significant of Fuzzy Based Statistical Tools}

The inferential statistical tools are commonly used to predict the characteristics of a population or to test the hypothesis based on the random sample. Very often, these tools are used to determine the relationship between two independent populations. In testing of hypothesis using classical set theory-based statistical tools, it is presumed that available data are precise. But, in the real-world problems the collected data may have some ambiguities or uncertainties. There are two types of uncertainties-randomness and fuzziness. Randomness involves uncertainties related to outcomes of an experiment. On the other hand, fuzziness involves uncertainties due to imprecision/vagueness in the data.

To deal with the uncertainties incurred in the statistical analysis of a real-world problem, the researcher needs the tools those can gauge these uncertainties. Fuzzy set introduced by Zadeh (1965) has the capability to capture the uncertainty in measurement. Since the inception of fuzzy set theory, many researchers have worked on the "fuzzification" of the statistical tools. Grzegorzewski (1998) introduced a method for statistical inference about 
the median of a population based on fuzzy random variables (FRV). He demonstrated a straightforward generalization of some classical non-parametric tests for FRV (Grzegorzewski, 2004). Arnold (1998) discussed the fuzzy hypothesis testing with crisp data. Casals and Gil (1989) proposed the Bayesian sequential tests for fuzzy parametric hypothesis from fuzzy information. Also, they considered the Neyman-Pearson type testing of hypothesis. Montenegro et al. (2001) presented a method to test the fuzzy means of a FRV. Akbari and Rezaei (2009) studied a bootstrap method for inference about the variance based on fuzzy data. Parchami et al. (2005) investigated a fuzzy version of some process capability indices when specification limits are fuzzy rather than precise.

In the current study, the hypothesis "Animation will facilitate student's performance equally when it is used for teaching different subjects," is tested by using fuzzy set theory based statistical tools. Here, it is considered that $\tilde{d}_{M}, \tilde{d}_{S}$ and $\tilde{d}_{L}$ are the fuzzy perception of the random variable $d_{M}, d_{S}$ and $d_{L}$ representing the difference of scores of the students in three different groups Mathematics, Science, and Language, respectively. It is well perceived that when operating with fuzzy numbers, the results of the calculations strongly depend on the shape of their membership functions. Less regular membership functions lead to more complicated calculations. On the other hand, fuzzy numbers with simpler shapes, such as triangular and trapezoidal, have a more intuitive and natural interpretation (Tyagi and Akram, 2013). All these reasons bring about a natural need for simple approximation of fuzzy numbers, such as triangular and trapezoidal, which are easy to handle. Therefore, in the present study, the triangular fuzzy number $(a, b, c)$ in symmetric form $(b-a=c-b)$ have been chosen to characterize the FRVs $\tilde{d}_{E}$ and $\tilde{d}_{C}$.

\section{Data Analysis and Interpretation}

\subsection{Details of the Study Results}

The current study was conducted with the total sample size of 25 students belonging to different demographic backgrounds as shown in Table 1. Table 2 demonstrates the average marks obtained by the students in the pre-test and post-test in different subjects like-Mathematics, Science and Language with the Standard Deviation.

\subsection{Testing Hypothesis with Fuzzy Numbers}

To test the hypothesis that "Animation will facilitate student's performance equally when it is used for teaching different subjects." performance in different subjects' the study was conducted on a sample of 25 students of two schools in an Indian state Karnataka. To measure the impact of animation on the academic performance of

\begin{tabular}{|c|c|c|c|}
\hline \multicolumn{2}{|c|}{ Variables } & No. of Students & Percentage \\
\hline \multirow{2}{*}{ Gender } & Male & 11 & $44 \%$ \\
\hline & Female & 14 & $56 \%$ \\
\hline \multirow{3}{*}{ Class } & Second & 9 & $36 \%$ \\
\hline & Fourth & 7 & $28 \%$ \\
\hline & Sixth & 9 & $36 \%$ \\
\hline \multirow{2}{*}{ District } & Bengaluru & 10 & $40 \%$ \\
\hline & Dakshina Kannada & 15 & $60 \%$ \\
\hline
\end{tabular}

Table 2. Details of marks secured by students in three different subjects.

\begin{tabular}{|c|c|c|c|c|c|c|c|c|c|c|c|c|}
\hline & \multicolumn{4}{|c|}{ Mathematics } & \multicolumn{4}{|c|}{ Science } & \multicolumn{4}{|c|}{ Language } \\
\hline & \multicolumn{2}{|c|}{ Control } & \multicolumn{2}{|c|}{ Exp. } & \multicolumn{2}{|c|}{ Control } & \multicolumn{2}{|c|}{ Exp. } & \multicolumn{2}{|c|}{ Control } & \multicolumn{2}{|c|}{ Exp. } \\
\hline & Pre & Post & Pre & Post & Pre & Post & Pre & Post & Pre & Post & Pre & Post \\
\hline Mean Score & 7.25 & 8.75 & 7.32 & 9.48 & 5.4 & 9.25 & 5.88 & 9.88 & 6.92 & 9.63 & 8.36 & 11.44 \\
\hline Standard Deviation & 3.9 & 3.21 & 3.35 & 3.1 & 2.76 & 4.28 & 2.74 & 2.89 & 3.48 & 4.03 & 4.8 & 5.4 \\
\hline
\end{tabular}


the students in different subjects, the average difference of their score in pre-test and post-test in control and experimental group was calculated. A comparison between the differences of scores of experimental group was made to understand the level of impact of animation on the students of three different subjects namely mathematics, science and language. Generally, if the difference between marks of the pre-test and post-test is different in each subject, the animation based teaching method has unequal impact in these subjects. Here too, it is presumed that the use of animation has a significant impact on improving the students' academic performance irrespective of their subject. The difference between scores of pre-test and post-test $d_{M}, d_{S}$ and $d_{L}$ in mathematics, science and language, respectively, is expected to be different.

However, this study also considers the fact that some extraneous factors too can contribute to this difference. These extraneous factors may include the psychological status of the student, their exposure to the technology, socio-economic background, the difference in the mode of teaching material used, etc. To capture this uncertainty incurred in the difference of their score, the present study employed a fuzzy set theoretic approach while testing the hypothesis. In this method, it is considered that $\tilde{d}_{M}, \tilde{d}_{S}$ and $\tilde{d}_{L}$ are fuzzy perception of the random variables $d_{M}, d_{S}$ and $d_{L}$. A TFN $(a, b, c)$ in symmetric form $(b-a=c-b)$ is assigned to each of the FRV $\tilde{d}_{M}, \tilde{d}_{S}$ and $\tilde{d}_{L}$. Without any loss of generality, one can assume that the difference of scores is positively correlated with the uncertainty incurred therein. Therefore, to maintain the uniformity in the selection of TFNs for the FRVs $\tilde{d}_{M}, \tilde{d}_{S}$ and $\tilde{d}_{L}$, it is assumed that the length $b-a=c-b$ for each fuzzy number $(a, b, c)$ is increasing proportionally with the increment in the difference of scores in pre and post-test for the students. Furthermore, it is quite obvious that most of the times this difference is non-negative. But, there are cases where it appears to be negative too. In the present work as mentioned above, the TFN are assigned to the FRVs $\tilde{d}_{M}$, $\tilde{d}_{S}$ and $\tilde{d}_{L}$ representing the fuzzy perception of the random variables $d_{M}, d_{S}$ and $d_{L}$, respectively. The TFNs assigned to the FRVs $\tilde{d}_{M}, \tilde{d}_{S}$ and $\tilde{d}_{L}$, and their corresponding $\alpha$-cut for the non-negative values of the random variables $d_{M}, d_{S}$ and $d_{L}$, respectively are listed in Table 3 .

In a similar manner, the TFNs assigned to the FRVs $\tilde{d}_{M}, \tilde{d}_{S}$ and $\tilde{d}_{L}$, and their corresponding $\alpha$-cut for the negative values of the random variable $d_{M}, d_{S}$ and $d_{L}$, respectively are listed in Table 4.

In the present study, since the significance of impact of animation is being measured for three different populations, the one factor ANOVA is the most suitable statistical tool for hypothesis testing. Herein, the ANOVA model with fuzzy data will be used for hypothesis testing. As we know that the $\alpha$-cut of the FRV is an interval, the one-factor ANOVA with fuzzy data will be converted into the two hypothesis testing of one-factor ANOVA models with crisp data termed as lower level model and upper-level model.

Further, let $x_{i j}^{L}$ and $x_{i j}^{U}$ will be the lower and upper interval values of the $\alpha$-cut of TFN representing the fuzzy perception of difference of scores of $j^{\text {th }}$ member of the $i^{\text {th }}$ group. Using the arithmetic of intervals, the

\begin{tabular}{|c|c|c|c|c|c|c|c|c|}
\hline \multirow{2}{*}{$\begin{array}{c}\text { Difference } \\
\text { (Non-negative) } \\
\text { in scores }\end{array}$} & \multirow[b]{2}{*}{ TFN } & \multirow[b]{2}{*}{$\alpha$-cut of TFN } & \multicolumn{2}{|c|}{ Mathematics } & \multicolumn{2}{|c|}{ Science } & \multicolumn{2}{|c|}{ Language } \\
\hline & & & $\begin{array}{l}\text { No. of } \\
\text { students }\end{array}$ & $\%$ & $\begin{array}{c}\text { No. of } \\
\text { students }\end{array}$ & $\%$ & $\begin{array}{l}\text { No. of } \\
\text { students }\end{array}$ & $\%$ \\
\hline 0 & $(-0.2,0,0.2)$ & {$[-0.2+0.2 \alpha, 0.2+0.2 \alpha]$} & 2 & 8 & 0 & 0 & 1 & 4 \\
\hline 1 & $(0.8,1,1.2)$ & {$[0.8+0.2 \alpha, 1.2-0.2 \alpha]$} & 4 & 16 & 3 & 12 & 0 & 0 \\
\hline 2 & $(1.75,2,2.25)$ & {$[1.75+0.25 \alpha, 2.25-0.25 \alpha]$} & 8 & 32 & 3 & 12 & 8 & 32 \\
\hline 3 & $(2.7,3,3.3)$ & {$[2.7+0.3 \alpha, 3.3-0.3 \alpha]$} & 5 & 20 & 2 & 8 & 3 & 12 \\
\hline 4 & $(3.6,4,4.4)$ & {$[3.6+0.4 \alpha, 4.4-0.4 \alpha]$} & 4 & 16 & 6 & 24 & 5 & 20 \\
\hline 5 & $(4.55,5,5.45)$ & {$[4.55+0.45 \alpha, 5.45-0.45 \alpha]$} & 1 & 4 & 1 & 4 & 3 & 12 \\
\hline 6 & $(5.5,6,6.5)$ & {$[5.5+0.5 \alpha, 6.5-0.5 \alpha]$} & 0 & 0 & 6 & 24 & 1 & 4 \\
\hline 7 & $(6.45,7,7.55)$ & {$[6.45+0.55 \alpha, 7.55-0.55 \alpha]$} & 0 & 0 & 2 & 8 & 2 & 8 \\
\hline 8 & $(7.4,8,8.6)$ & {$[7.4+0.6 \alpha, 8.65-0.6 \alpha]$} & 0 & 0 & 1 & 4 & 0 & 0 \\
\hline
\end{tabular}


Table 4. $\alpha$-cut of the TFNs assigned to the FRVs $\tilde{d}_{E}$ and $\tilde{d}_{C}$ (For negative difference).

\begin{tabular}{ccccccccc}
\hline \multirow{2}{*}{$\begin{array}{c}\text { Difference } \\
\text { (Negative) }\end{array}$} & TFN & $\alpha$-cut of TFN & \multicolumn{2}{c}{ Maths } & \multicolumn{2}{c}{ Science } & \multicolumn{2}{c}{ Language } \\
\cline { 5 - 9 } in scores & & $\begin{array}{c}\text { No. of } \\
\text { students }\end{array}$ & $\%$ & $\begin{array}{c}\text { No. of } \\
\text { students }\end{array}$ & $\%$ & $\begin{array}{c}\text { No. of } \\
\text { students }\end{array}$ & $\%$ \\
\hline-1 & $(-1.2,-1,-0.8)$ & {$[-1.2+0.2 \alpha,-0.8-0.2 \alpha]$} & 0 & 0 & 0 & 0 & 1 & 4 \\
-2 & $(-2.5,-2,-1.75)$ & {$[-2.25+0.25 \alpha,-1.75-0.25 \alpha]$} & 1 & 4 & 1 & 4 & 1 & 4 \\
\hline
\end{tabular}

grand mean of lower and upper interval values $\tilde{x}^{L}$ and $\tilde{X}^{U}$, respectively is computed for the intervals representing the $\alpha$-cut of the TFNs as given in Table 3 and Table 4 for all the students in three groups as:

$$
\left.\bar{x}^{L}=2.743+0.337 \alpha ; \bar{x}^{U}=3.417-0.337 \alpha\right\} ; \text { Grand mean }
$$

Similarly, the mean $\tilde{x}_{i}^{L}$ and $\tilde{x}_{i}^{U}$ of lower and upper interval values, respectively for the intervals representing the $\alpha$-cut of the TFNs of the ith group is computed for all three groups as:

$$
\begin{gathered}
\left.\bar{x}_{1}^{L}=1.88+0.28 \alpha ; \bar{x}_{1}^{U}=2.44-0.28 \alpha\right\} ; \text { Group mean for first group (Mathematics) } \\
\left.\bar{x}_{1}^{L}=3.61+0.39 \alpha ; \bar{x}_{1}^{U}=4.39-0.39 \alpha\right\} ; \text { Group mean for second group (Science) } \\
\left.\bar{x}_{1}^{L}=2.74+0.34 \alpha ; \bar{x}_{1}^{U}=3.42-0.34 \alpha\right\} ; \text { Group mean for third group (Language) }
\end{gathered}
$$

Further, the sum of squared deviations about the grand mean (SST) across all 75 observations is calculated for the lower and upper interval values of the corresponding $\alpha$-cut as follows:

$$
\mathrm{SST}=\left[0.9467 \alpha^{2}+31.8667 \alpha+318.7067,0.9467 \alpha^{2}-35.6533 \alpha+386.2267\right] .
$$

Similarly, the sum of squared deviations for all observations within each group from that group mean, summed across all groups is obtained as follows:

$$
\operatorname{SST}_{\mathrm{E}}=\left[0.795 \alpha^{2}+27.11 \alpha+281.295,0.795 \alpha^{2}-30.29 \alpha+338.695\right] .
$$

It is well established that the sum of squared deviations about the grand mean (SST) is equal to the sum of squared deviations for each group mean about the grand mean $\left(\mathrm{SST}_{\mathrm{G}}\right)$ plus the sum of squared deviations for all observations within each group from that group mean, summed across all groups $\left(\mathrm{SST}_{\mathrm{E}}\right)$ i.e.

$$
\mathrm{SST}=\mathrm{SST}_{\mathrm{G}}+\mathrm{SST}_{\mathrm{E}} \text {. }
$$

Using this relation, the $\mathrm{SST}_{\mathrm{G}}$ is computed as follows:

$$
\operatorname{SST}_{\mathrm{G}}=\left[0.1517 \alpha^{2}+4.7567 \alpha+37.4117,0.1517 \alpha^{2}-5.3633 \alpha+47.5317\right] \text {. }
$$

The mean squared deviation $M S_{G}$ and $M S_{E}$ for lower and upper interval values are computed to obtain the $\alpha$-cut of the TFNs representing the mean squared deviation $M S_{G}$ and the mean squared deviation $M S_{E}$, respectively.

$$
\begin{aligned}
{ }^{\alpha} M S_{G} & =\left[0.0758 \alpha^{2}+2.3783 \alpha+18.7058,0.0758 \alpha^{2}-2.6817 \alpha+23.7658\right] \\
{ }^{\alpha} M S_{E} & =\left[0.0110 \alpha^{2}+0.3765 \alpha+3.9069,0.0110 \alpha^{2}-0.4207 \alpha+4.7041\right]
\end{aligned}
$$

Finally, the F-value for lower as well as upper interval values are computed for different values of $\alpha \in[0,1]$ and listed in Table 5.

From Table 5, it can be observed that the lower and upper interval F-value $F^{\mathrm{L}}$ and $F^{\mathrm{U}}$, respectively are greater than the critical F-value 3.1239 (one-tail) for all values of $\alpha \in[0,1]$. Therefore, the null hypothesis is rejected and the alternative hypothesis "Animation will not facilitate student's performance equally when it is used for teaching different subjects." is accepted even after considering all uncertainties due to imprecision and vagueness in collected data. 
Table 5. The lower and upper interval F-value with respect to $\alpha$.

\begin{tabular}{ccc}
$\alpha$ & $F^{\mathrm{L}}$ & $F^{\mathrm{U}}$ \\
0 & 3.9765 & 6.0830 \\
0.1 & 4.0635 & 5.9571 \\
0.2 & 4.1521 & 5.8335 \\
0.3 & 4.2426 & 5.7123 \\
0.4 & 4.3348 & 5.5935 \\
0.5 & 4.4288 & 5.4769 \\
0.6 & 4.5246 & 5.3627 \\
0.7 & 4.6224 & 5.2506 \\
0.8 & 4.7220 & 5.1407 \\
0.9 & 4.8237 & 5.0330 \\
$\mathbf{1}$ & 4.9273 & 4.9273 \\
\hline
\end{tabular}

\section{Discussion}

The study shows that in all three subjects students have improved their performance when they studied using animation. The final results (Table 2) of the study shows that students in the mathematics subject the students control group scored an average of 7.25 in pre-test and 8.75 in post-test. The difference (impact of traditional teaching) between the two tests is 1.5 . While in the experimental group, where animation instructional materials were used in teaching, 7.32 was the mean score obtained by students in pre-test was and in post-test the average score was 9.48. The difference in scores between pre-test was slightly higher (2.16) when compared to control group. This indicates that animation has played a positive role in felicitating students learning in Mathematics. However, as shown in the Table 3, there are significant variations in the marks obtained by the students even in experimental group. Only 88\% of the students in experimental group have improved their marks when they studied using animation. Their score difference in pre-test and post-test is ranging from 1 to 5 . Other $8 \%$ of the students did not record any progress, they obtained the same marks both in pre-test and post-test in experimental group. But, for the $4 \%$ students, the use of animation has negatively affected. Their performance has come down in post-test.

As shown in Table 2, in the science subject, the students who studied using traditional "chalk and talk" method, scored an average of 5.4 in pre-test and 9.25 in post-test. The difference (impact of traditional teaching) between the two tests is 3.85. In the experimental group, 5.88 was the mean score obtained by students in pre-test. In the post-test, their average score was 9.88. The difference in the scores between pre-test and post-test was 4 , which is significantly higher compared to the control group. This shows animation has played crucial role in improving students' academic performance. When studying science subject $96 \%$ of the students have improved their performance and their mark difference between pre-test and post-test ranges from 1 - 8 . However, $4 \%$ the students got less marks, after studying with animation.

In Language (Kannada) the students belong to control group scored mean score of 6 . The difference between the scores in these two test are 2.71. The students in experimental group recorded score of 8.36 and 11.44 respectively in pre-test and post-test respectively and the difference between the scores of these tests is 3.08. This shows students performed better when they used animation instructional material for their study. The analysis of the result also shows that $88 \%$ of the students got positive stimulus from animation and they have shown improvement of 2 - 7 marks when they studied using animation. But, for $4 \%$ students, it did not make any difference. The study also reveals that $8 \%$ of the students performed poorly after studying with animation.

The hypothesis test done using fuzzy shows that even after considering the extraneous factors involved in the study, it is proved that animation is not facilitating student's performance equally when it is used in teaching different subjects. The analysis of the scores obtained by the students provides sufficient evidence for this. In Science subject, the score difference in pre-test and post-test was 4 when animation is used. But, in Language, it 
was 3.08 and in mathematics it was just 2.16. It clearly indicates that among the three subjects selected, animation had high positive effect on students' performance when they studied Science subject. Even though students performed better when animation is used to teach Mathematics, the degree of improvement was low when compared to other subjects.

The researcher observed during the course of the study that the students, especially of class second and fourth, while studying Mathematics were attracted by the animation instructional material used. As the mathematical problems were in the form of animated stories, students easily understood the subject. However, when they started solving the math problem they were relying mostly on use of fingers and other traditional techniques for calculation. In the language subject, the animation content were interactive, here every student had to click the right answer, in order to understand the proper use of various topics on grammar. Students enjoyed learning the Language subject with animation. However, here they were more curious to know the technicalities of interactive animation. In Science subject, where students have shown high improvement, the curriculum was encoded in the form of catchy rhymes. Teacher presented several topics with catchy rhymes and animation. Here, animation content helped the students to have proper visualization on complex science topics and catchy tunes enabled them to register the key words, concepts in students mind easily, which helped them to memorize in a better way.

\section{Limitations and Scope of Further Research}

The study has some limitations. The study has been conducted with a small sample size of 25 students. Animation material used in the experimental study was prepared by Ajim Premji foundation and was approved by govt. of Karnataka to be used in the schools of Karnataka. The researcher had hardly any control over the design.

This study was conducted on students of second, fourth, sixth standard; taking animation instructional content of mathematics, language and science subjects, as the sample. The study can be extended to every class and to various other subjects as well. Here in the study, it is observed that the use of animation does not have equal positive effect on students' academic performance in different subjects. However, the clear reasons for this are still unknown. It can be further studied extended using higher levels of statistical tools to identify the motivational, behavioral, cognitive, psychological and pedagogical factors influencing students while the animation is used in the process of teaching and learning.

\section{Conclusion}

With the help of computer-mediated communication techniques, especially by using tools like animation, teachers are able to give distinct learning experience to the students. In general, animation can help to present a complex concept in a simpler form, to create interest among the students, to motivate towards learning and to draw students' attention on particular subjects, which eventually facilitate better learning.

Use of animation can turn the students into active participants and co-producers of knowledge and enhance learning abilities of students in modern classroom set up and it can provide positive stimulus to students in most of the subjects they study. However, the degree of improvement in students' academic performance may largely depend on the design of the animated content and also on the mode of presentation of instruction material in the classroom.

\section{Acknowledgements}

The authors acknowledge and extend their heartfelt gratitude to the editor and anonymous reviewer for their careful reading of this paper and constructive suggestions.

\section{References}

Akbari, M. G., \& Rezaeim, A. (2009). Bootstrap Statistical Inference for the Variance Based on the Data. Austrian Journal of Statistics, 38, 121-130.

Arnold, B. F. (1998). Testing Fuzzy Hypothesis with Crisp Data. Fuzzy Sets and Systems, 94, 323-333. http://dx.doi.org/10.1016/S0165-0114(96)00258-8

Betrancourt, M., \& Chassot, A. (2008). Making Sense of Animation: How Do Children Explore Multimedia Instruction? In R. Lowe, \& W. Schnotz, (Eds.), Learning with Animation: Research Implications for Design (pp. 149-164). New York: 
Cambridge UP.

Casals, M. R., \& Gil, M. A. (1989). A Note on Operativeness of Neyman-Pearson Tests with Fuzzy Information. Fuzzy Sets and Systems, 30, 215-220. http://dx.doi.org/10.1016/0165-0114(89)90082-1

Chizmar, J., \& Walbert, M.(1999). Web-Based Learning Environments Guided by Principles of Good Teaching Practice. The Journal of Economic Education, 30, 248-259. http://dx.doi.org/10.1080/00220489909595985

Easingwood, N. (2000). Electronic Communication in the Twenty-First-Century Classroom. In N. Gamble, \& N. Easingwood (Eds.), ICT and Literacy (pp. 45-58). New York: Continnum.

Fine, C., \& Thornbury, M. L. (2006). ICT Play and Exploration. In M. Hayes, \& D. Whitebread (Eds.), ICT in Years (pp. 21-37). New York: Open University Press.

Grzegorzewski, P. (1998). Statistical Inference about the Median from Vague Data. Control and Cybernatics, 27, 447-464.

Grzegorzewski, P. (2004). Distribution-Free Tests for Vague Data. Soft Methodology and Random Information Systems (pp. 495-502). Heidelberg: Springer. http://dx.doi.org/10.1007/978-3-540-44465-7_61

Hegarty, M., \& Kriz, S. (2008). Effects of Knowledge and Spatial Ability on Learning from Animation. In R. Lowe, \& W. Schnotz (Eds.), Learning with Animation: Research Implications for Design (pp. 1-27). New York: Cambridge UP.

Mayer, R. E. (2008). Research Based Principles for Learning with Animation. In L. Richard, \& W. Schnotz (Eds.), Learning with Animation: Research Implications for Design (pp. 30-46). New York: Cambridge UP.

Molenda, M., \& Sullivan, M. (2003). Issues and Trends in Instructional Technology. In Branch, \& R. Marbie (Eds.), Education and Media Technology Year Book (pp. 3-21). London: Libraries Unlimited.

Montenegro, M., Casals, M. R., Lubiano, M. A., \& Gil, M. A. (2001). Two-Sample Hypothesis Tests of Means of a Fuzzy Random Variable. Information Sciences, 133, 89-100. http://dx.doi.org/10.1016/S0020-0255(01)00078-0

Narayanan, N. H., \& Hegarty, M. (1998). On Designing Comprehensible Hypermedia Manuals. International Journal of Human Computer Studies, 48, 267-301. http://dx.doi.org/10.1006/ijhc.1997.0169

Parchami, A., Mashinchi, M., Yavari, A. R., \& Reza, H. (2005). Process Capability Indices as Fuzzy Numbers. Austrian Journal of Statistics, 34, 391-402.

Pearson J. C., Nelson, P. E., Titsworth, S., \& Harter, L. (2011). Human Communication (4th ed.). New York: Macgrow.

Rogers, Y. (2008). A Comparison of How Animation Has Been Used to Support Formal, Informal, and Playful Learning. In L. Richard, \& W. Schnotz (Ed.), Learning with Animation: Research Implications for Design (pp. 286-303). New York: Cambridge UP.

Schontz, W., \& Rasch, T. (2008). Functions of Animation in Comprehension and Learning. In L. Richard, \& W. Schnotz (Ed.), Learning with Animation: Research Implications for Design (pp. 92-113). New York: Cambridge UP.

Tyagi, S. K., \& Akram, M. (2013). Human Reliability Evaluation for Offshore Platform Musters Using Intuitionistic Fuzzy Sets. IEEE Transactions on Fuzzy Systems, 21, 1115-1122. http://dx.doi.org/10.1109/TFUZZ.2013.2243734

Wrench, J. S., Virginia, P. R., \& Joan (2009). Communication, Affect \& Learning in the Classroom (3rd ed.). CA: Virginia Peck Richmond.

Younger, T., \& Narayanan, H. (2008). Turning the Table: Investigating Characteristics and Efficacy of Student Authored Animations and Multimedia Representations. In L. Richard, \& W. Schnotz (Ed.), Learning with Animation: Research Implications for Design (pp. 263-268). New York: Cambridge UP.

Zadeh, L. A. (1965). Fuzzy Sets. Information and Control, 8, 338-353. http://dx.doi.org/10.1016/S0019-9958(65)90241-X 


\section{Submit or recommend next manuscript to SCIRP and we will provide best service for you:}

Accepting pre-submission inquiries through Email, Facebook, LinkedIn, Twitter, etc.

A wide selection of journals (inclusive of 9 subjects, more than 200 journals)

Providing 24-hour high-quality service

User-friendly online submission system

Fair and swift peer-review system

Efficient typesetting and proofreading procedure

Display of the result of downloads and visits, as well as the number of cited articles

Maximum dissemination of your research work

Submit your manuscript at: http://papersubmission.scirp.org/ 